\title{
Application of Nanomagnetic NH 2 .MIL-101(Fe)/ED as a Retrievable and Efficient Catalyst for the Synthesis of 2,6-Diamino-4-Aryl-4H-Thiopyran- 3,5- Dicarbonitrile Derivatives
}

Firouz Matloubi Moghaddam ( $\nabla$ matloubi@sharif.edu )

Sharif University of Technology

\section{Bagher Aghamiri}

Sharif University of Technology

Aida Yazdani Motlagh

Sharif University of Technology

Atefeh Jarahiyan

Sharif University of Technology

\section{Research Article}

Keywords: NH2.MIL-101(Fe), Basic MOF, 4H-Thiopyran- 3, 5- dicarbonitrile

Posted Date: February 3rd, 2022

DOI: https://doi.org/10.21203/rs.3.rs-1273458/v1

License: (c) (i) This work is licensed under a Creative Commons Attribution 4.0 International License.

Read Full License 


\section{Abstract}

In this publication, we reported an efficient one-pot, four-component procedure for the synthesis of 2,6diamino-4-Aryl-4H-Thiopyran-3,5-dicarbonitrile derivatives by a reaction between primary amines, carbon disulfide, malononitrile, and benzylidenemalononitrile in the presence of magnetic $\mathrm{NH}_{2} \cdot \mathrm{MIL}-101(\mathrm{Fe}) / \mathrm{ED}$ as a basic metal organic framework catalyst. Magnetic $\mathrm{NH}_{2}$.MIL-101(Fe)/ED was synthesized through anchoring $\mathrm{FeCl}_{3}$ on $\mathrm{CoFe}_{2} \mathrm{O}_{4}$ magnetic nanoparticles surface and then 2-aminoterphthalic acid was used to form MOF structure. At the final step, metal centers were modified with ethylenediamine (ED). The different techniques such as Fourier transmission infrared spectroscopy, X-ray diffraction, Field emission scanning electron microscopy, Transmission electron microscopy, Brunauer-Emmett-Teller analysis, and Thermogravimetric analysis were used to characterize the structure of the catalyst. Using X-ray crystallography, the structure of the final product was also determined.

\section{Introduction}

Catalysts act as the dynamo of many chemical transformations and are responsible for accelerating the rate of reactions. ${ }^{1}$ The development of metal-organic frameworks (MOFs) as strong catalysts in organic transformations is highly in demand because they could catalyze a large number of chemical reactions such as the preparation of prominent heterocyclic scaffolds. ${ }^{2,3}$

Heterocycles as one of the most important classes of organic compounds become more widespread each year. ${ }^{4,5}$ More than half of known compounds are heterocycles which a great many of them could be found in a variety of organic structures such as drugs, natural products, and most natural dyes. Among the heterocycles, sulfur-containing heterocyclic compounds (S-heterocycles) are of particular importance as a versatile scaffold for synthetic organic chemists and therefore tremendous attention is being paid to afford them. One easy way to synthesize S-heterocycles is to use dithiocarbamates. They are introduced to be worthy due to their exploitation in the construction of S-heterocycles with biological activity. ${ }^{6-13}$

Among the S-heterocycles, thiopyran frameworks are known as maneuverable skeletons and therefore have been subject to extensive study due to their unique properties such as the anticancer, and antimicrobial activities. ${ }^{14-23}$ Meanwhile, tricyclic thiopyran-2-one compounds are of use in the therapies for the treatment of viral infections and diseases including AIDS which further emphasize that these organic skeletons are likely to be of considerable practical significance. ${ }^{24}$ Hence, chemists are hunting new ways to create various S-heterocycles and therefore a great deal of synthetic ways have been developed for the construction of these structures. For example, Rajabi and co-workers reported antiproliferative activity of novel thiopyran analogs on MCF-7 breast and HCT- 15 colon cancer cells. ${ }^{25}$ Recently, Asghari et al. developed an efficient method for the synthesis of sulfide, sulfoxide, and sulfone derivatives of thiopyran and then evaluated the antibacterial and antifungal activities of these synthesized materials. Moreover, they showed these materials are highly effective with respect to grampositive and gram-negative bacteria, as well as the fungus Candida albicans. ${ }^{26} \ln 2012$, Singh et al. 
reported 4-dimethylamino pyridine-promoted one-pot three-component regioselective synthesis of highly functionalized $4 H$-thiopyrans via heteroannulation of $\beta$-Oxodithioesters. ${ }^{27}$ Synthesis and pharmacological evaluation of thiopyran analogues was also reported by Vliet et al. ${ }^{28}$ Considering the above evidence of the thiopyrans importance in medicinal chemistry as well as our interest in developing trends toward the synthesis of thiopyran scaffolds, herein we report an efficient one-pot, four-component procedure for the synthesis of 2,6-diamino-4-Aryl-4H-Thiopyran-3,5-dicarbonitrile derivatives by a reaction between primary amines, carbon disulfide, malononitrile, and benzylidenemalononitrile in the presence of magnetic MOF-based catalytic system as an efficient basic catalyst for the synthesis of thiopyran derivatives (Figure 1).

\section{Result And Discussion}

\section{Catalyst preparation.}

Figure 2 illustrates the catalyst preparation procedure briefly. Magnetic $\mathrm{NH}_{2} \cdot \mathrm{MIL}-101(\mathrm{Fe}) / \mathrm{ED}$ was synthesized due to act as a basic catalyst for the synthesis of thiopyran derivatives. The use of spinel ferrites offers the catalyst magnetic properties along with their high activity in organic transitions. ${ }^{29}$ Also, the purpose of using Fe-based MOFs was to profit from their high catalytic activity and environmentally friendly properties. ${ }^{30}$ First of all, $\mathrm{CoFe}_{2} \mathrm{O}_{4}$ NPs were synthesized with the co-precipitation method and then $\mathrm{FeCl}_{3} \cdot 6 \mathrm{H}_{2} \mathrm{O}$ and $\mathrm{NH}_{2}-\mathrm{BDC}$ were used to form the $\mathrm{NH}_{2} \cdot \mathrm{MIL}-101(\mathrm{Fe})$ structure. Finally, ED was grafted to metal centers to improve the basic nature of the catalyst. ${ }^{31}$

\section{FT-IR spectroscopy}

FT-IR spectroscopy is a simple apparatus to confirm functional groups on the catalyst. Figure 3 presents the FT-IR spectra of magnetic $\mathrm{NH}_{2} \cdot \mathrm{MIL}-101(\mathrm{Fe})$ and magnetic $\mathrm{NH}_{2} \cdot \mathrm{MIL}-101(\mathrm{Fe}) / \mathrm{ED}$. The benzenecarboxylates characteristic bands of $\mathrm{NH}_{2}-\mathrm{BDC}$ can be seen in both FT-IR spectra. The bands at $1575 \mathrm{~cm}^{-1}$ for magnetic $\mathrm{NH}_{2} \cdot \mathrm{MIL}-101(\mathrm{Fe})$ and $1568 \mathrm{~cm}^{-1}$ for magnetic $\mathrm{NH}_{2} \cdot \mathrm{MIL}-101(\mathrm{Fe}) / \mathrm{ED}$ are assigned to $\mathrm{C}=0$ bonding in benzene-carboxylates. ${ }^{32}$ In addition, the presence of amino groups of benzene ring was confirmed by the bands at 1255 and $1253 \mathrm{~cm}^{-1}$ for magnetic $\mathrm{NH}_{2} \cdot \mathrm{MIL}-101(\mathrm{Fe})$ and magnetic $\mathrm{NH}_{2} \cdot \mathrm{MIL}-$ 101(Fe)/ED aromatic C-N stretching mode, respectively. ${ }^{33}$ The doublet at 3368 and $3463 \mathrm{~cm}^{-1}$ is related to $\mathrm{NH}_{2}$ groups of magnetic $\mathrm{NH}_{2} \cdot \mathrm{MIL}-101(\mathrm{Fe})$ (Figure 3a). The spectrum of $\mathrm{NH}_{2} \cdot \mathrm{MIL}-101(\mathrm{Fe}) / \mathrm{ED}$ depicts the doublet at 3416 and $3467 \mathrm{~cm}^{-1}$ for $\mathrm{NH}_{2}$ groups. The appearance of new peaks in the region of $1500-$ $1600 \mathrm{~cm}^{-1}$ for magnetic $\mathrm{NH}_{2}$.MIL-101(Fe)/ED is assigned to ED as a metal modifier (Figure 3b). ${ }^{34}$

\section{X-ray diffraction analysis}

The final catalyst was suitable for $\mathrm{X}$-ray diffraction analysis and the related pattern is provided in Figure 4. Some characteristic peaks for $\mathrm{CoFe}_{2} \mathrm{O}_{4}$ NPs and MIL-101(Fe) are observed in Figure 4. Reviewing the literature, it is found that the peaks at $2 \theta=18.3^{\circ}, 30.1^{\circ}, 33.2^{\circ}, 37.1^{\circ}, 43.1^{\circ}, 49.5^{\circ}, 64.1^{\circ}$ are assigned to 
MIL-101 $(\mathrm{Fe}){ }^{35,36}$ and the peaks at $2 \theta=30.1^{\circ}, 18.3^{\circ}, 35.4^{\circ}, 53.6^{\circ}, 57.1^{\circ}, 62.6^{\circ}, 75.3^{\circ}$ are matched with $\mathrm{CoFe}_{2} \mathrm{O}_{4}$ NPs (JCDPS no. 79-1744). ${ }^{37}$ Hence, the crystalline natures of the $\mathrm{CoFe}_{2} \mathrm{O}_{4}$ NPs and MIL-101(Fe) are confirmed by this analysis indicating the final catalyst was synthesized successfully.

\section{Thermogravimetric analysis (TGA)}

Thermal stability of the final catalyst was investigated by TGA analysis. Magnetic $\mathrm{NH}_{2} \cdot \mathrm{MIL}-101(\mathrm{Fe})$ and magnetic $\mathrm{NH}_{2} \cdot \mathrm{MIL}-101(\mathrm{Fe}) / \mathrm{ED}$ are stable up to $300{ }^{\circ} \mathrm{C}$ (Figure 5a and Figure $5 \mathrm{~b}$ ). The first weight losses are related to evaporating water capped into $\mathrm{NH}_{2} \cdot \mathrm{MIL}-101(\mathrm{Fe})$ pores. The second weight losses occur owing to degradation of $\mathrm{NH}_{2} \cdot \mathrm{MIL}-101$ (Fe) frameworks. ${ }^{38}$ Also, the magnetic $\mathrm{NH}_{2} \cdot \mathrm{MIL}-101$ (Fe)/ED curve shows more weight loss due to decomposition of ethylene diamine (ED) (Figure 5b).

\section{Morphology study}

The FE-SEM and TEM images of magnetic $\mathrm{NH}_{2} \cdot \mathrm{MIL}-101(\mathrm{Fe}) / \mathrm{ED}$ were taken to characterize the morphological structure of the final catalyst (Figure 6). The both analysis show that $\mathrm{CoFe}_{2} \mathrm{O}_{4} \mathrm{NPs}$ and $\mathrm{NH}_{2} \cdot \mathrm{MIL}-101(\mathrm{Fe})$ have sutaible combination with smoth surface. Based on TEM images, $\mathrm{CoFe}_{2} \mathrm{O}_{4} \mathrm{NPs}$ shows spherical shape with average particle size of $38 \mathrm{~nm}$ and $\mathrm{NH}_{2} \cdot \mathrm{MIL}-101(\mathrm{Fe}) / \mathrm{ED}$ indicates an octahedral stucture and their size is approximately $62 \mathrm{~nm}$. In addition, an example of magnetic $\mathrm{NH}_{2} . \mathrm{MIL}-$ 101(Fe)/ED has been shown with red circle in each FE-SEM and TEM images. Furthermore, the EDX pattern and the related elemental mapping images of the magnetic $\mathrm{NH}_{2} \cdot \mathrm{MIL}-101(\mathrm{Fe}) / \mathrm{ED}$ are indicated in Figure $7 \mathrm{a}$ and $7 \mathrm{~b}$. The homogeneous distribution of elements contained $\mathrm{C}, \mathrm{N}, \mathrm{O}, \mathrm{Fe}, \mathrm{Co}$ can be seen in the elemental mapping images.

\section{Brunauer-Emmett-Teller (BET)}

The specific surface area and pore properties of the magnetic $\mathrm{NH}_{2} \cdot \mathrm{MIL}-101(\mathrm{Fe})$ and magnetic $\mathrm{NH}_{2} \cdot \mathrm{MIL}-$ $101(\mathrm{Fe}) / \mathrm{ED}$ were studied by BET analysis and the data are summarized in Table 1 . It is noteworthy magnetic $\mathrm{NH}_{2} \cdot \mathrm{MIL}-101(\mathrm{Fe}) / \mathrm{ED}$ has a lower $\mathrm{BET}$ surface area which is maybe related to occupation of ED in some pores.

In continuation of our high interest on the synthesis of sulfur- containing heterocyclic compounds, we thoroughly investigated the synthesis of 2,6-diamino-4-Aryl-4H-Thiopyran-3,5- dicarbonitrile derivatives catalyzed by magnetic $\mathrm{NH}_{2}$.MIL-101(Fe)/ED as a basic MOF. At the outset of synthetic work, optimization the reaction conditions commenced with the reaction of carbon disulfide (1), methylamine (2a), banzylidene malononitrile (3a), and malononitrile (4) in the presence of magnetic $\mathrm{NH}_{2} \cdot \mathrm{MIL}-101(\mathrm{Fe}) / \mathrm{ED}$ as the model reaction (Table 2). To do this, initially, a mixture of carbon disulfide (1)(1 mmol), methylamine $(2 \mathrm{a})(1 \mathrm{mmol})$ in DCM $(1 \mathrm{ml})$ was mixed and stirred at room temperature for $5 \mathrm{~min}$, then benzylidene malononitrile (3a) $(1.2 \mathrm{mmol})$ and malononitrile $(4)(1.2 \mathrm{mmol})$ were added in the presence of magnetic $\mathrm{NH}_{2} \cdot \mathrm{MIL}-101(\mathrm{Fe}) / \mathrm{ED}$ catalyst $(5 \mathrm{mg})$ and stirred for more $30 \mathrm{~min}$ to afford the corresponding product (5a) in high yield. In the next step, the impact of different conditions such as catalyst, temperature, and solvent was studied on the model reaction. 
As shown in Table 2, not using a catalyst was resulted in low yield of the final product (entries 1-5). Also, the use of catalyst components separately provided a moderate yield of the desired product (entries 1318). In contrast, it is noteworthy that a cosiderable amount of 5 a was formed in the presence of magnetic $\mathrm{NH}_{2}$.MIL-101(Fe)/ED after 30 min in a smooth, meaningful manner (entry 11). Hence, magnetic $\mathrm{NH}_{2} \cdot \mathrm{MIL}^{-}$ 101(Fe)/ED chosen as the optimized catalyst for carrying out this reaction. As another attempt for increasing the yield of the final product, we changed the reaction temperature from ambient to reflux condition. It was observed that increasing the reaction temperature has no beneficial effect on reaction time and the yield of the final product (entries 8 and 12). In the next step of synthetic work, different solvents were screened. According to the achieved results, DCM was selected as an efficient solvent in this synthetic procedure. Encouraged by these promising results, the general scope of the reaction was investigated (Table 3). To our delight, the desired heterocyclic products were obtained in high yield.

The structure of the final products were characterized by ${ }^{1} \mathrm{H}$ NMR, ${ }^{13} \mathrm{C}$ NMR and IR spectral analysis. To prove the proposed final structure, the single crystal of 5 a was prepared and the structure of this molecule was also confirmed by $X$-ray crystallographic analysis (Figure S1).

To confirm the practicability of the designed protocol as a useful tool in organic synthesis, the reaction was enlarged into a gram scale (Figure S2). We were delighted to provide the product 5a in $90 \%$ yield. Next, the reaction mechanism was investigated. Therefore, the plausible mechanism proposed in Figure 8 seems to be resonable to define the sequence of steps in the reaction.

\section{Catalyst Recycling.}

To investigate recyclability of the magnetic $\mathrm{NH}_{2}$.MIL-101(Fe)/ED catalyst, a reaction between carbon disulfide, methyl amine, benzylidene malononitrile, and malononitrile were tested as model reaction. The catalyst was separated through an external magnetic field after each complete run. The recovered catalyst was washed with methanol several times. Then, it was completely dried under a vacuum oven and used for the next run. The recovered catalyst remained active during five successive runs and the result has been summarized in Figure S3. The FE-SEM and TEM images of the recovered catalyst are provided in Figure S4. It can be seen that there have not been significant changes in the catalyst morphology but the $\mathrm{NH}_{2}$.MIL-101(Fe) parts are slightly deformed after fifth runs.

\section{Conclusion}

In summary, regarding the huge potential value of MOFs in the construction of prominent organic molecules, we have reported an efficient magnetic MOF-based catalytic system for rapid construction of thiopyran scaffolds. This process does not suffer from drawbacks, such as multi-step syntheses, using expensive catalysts, rigorous reaction workup and long reaction time. Altogether, remarkable advances have been emerged by applying alternative reaction conditions and by using magnetic basic MOF 
catalyst to afford interesting final products. This catalytic system has shown extremely efficient activity for the synthesis of thiopyran derivatives in mild conditions with excellent yields.

\section{Experimental Section \\ Catalyst preparation}

A round-bottom flask was firstly charged with $0.4 \mathrm{~g}$ of $\mathrm{CoFe}_{2} \mathrm{O}_{4} \mathrm{NPs}$ and DMF $(15 \mathrm{~mL})$ and sonicated for $0.5 \mathrm{~h}$. It is noteworthy that $\mathrm{CoFe}_{2} \mathrm{O}_{4} \mathrm{NPs}$ was synthesized based on the reported procedure. ${ }^{8}$ The previous mixture was stirred at room temperature after adding $\mathrm{FeCl}_{3} \cdot 6 \mathrm{H}_{2} \mathrm{O}(2 \mathrm{~mol}, 0.54 \mathrm{~g})$ for $24 \mathrm{~h}$. Then, $1 \mathrm{~mol}$ of $\mathrm{NH}_{2}$-terphetalic acid ( $\mathrm{NH}_{2}$-BDC) was dissolved compeletely in $15 \mathrm{~mL}$ of DMF and added to the previous mixture. Finally, it was poured into a Teflon-lined autoclave and kept at $110^{\circ} \mathrm{C}$. After $24 \mathrm{~h}$, the mixture was collected by an external magnetic field. Afterward, the obtained mixture was dispersed in about 50 $\mathrm{ml}$ of chloroform and stirred for $24 \mathrm{~h}$. The mixture separation was performed by an external magnetic field and washed with chloroform three times named magnetic $\mathrm{NH}_{2} \cdot \mathrm{MIL}-101(\mathrm{Fe})$. In the next step, $0.5 \mathrm{~g}$ of magnetic $\mathrm{NH}_{2} \cdot \mathrm{MIL}-101(\mathrm{Fe})$ was kept in a vacuum oven at $150{ }^{\circ} \mathrm{C}$ for $24 \mathrm{~h}$ to completely dehydrate. Then, it was suspended in $30 \mathrm{~mL}$ of anhydrous toluene and $0.75 \mathrm{mmol}$ of ED was added into the flask. The flask was equipped with a condenser and refluxed for $24 \mathrm{~h}$. The final catalyst was recovered by an external magnetic field and washed with ethanol three times. After drying under a vaccum oven at $60^{\circ} \mathrm{C}$, magnetic $\mathrm{NH}_{2} \cdot \mathrm{MIL}-101(\mathrm{Fe}) / \mathrm{ED}$ was obtained as a black solid.

Catalytic performance for the synthesis of 2,6-diamino-4-Aryl-4 $\mathrm{H}$-Thiopyran-3,5- dicarbonitrile derivatives (5a-5o)

To a solution of primary amines $(1 \mathrm{mmol})$ in DCM $(1 \mathrm{ml})$, Carbon disulfide $(1 \mathrm{mmol})$ was added and stirred at room temperature for $5 \mathrm{~min}$. Then malononitrile $(1.2 \mathrm{mmol})$, and benzylidene malononitrile $(1.2 \mathrm{mmol})$ were added to previous mixture in the presence of magnetic $\mathrm{NH}_{2} \cdot \mathrm{MIL}-101(\mathrm{Fe}) / \mathrm{ED}$ and stirred for more 30 min to afford the corresponding products (5a-5o) in high yield. To purify the product, the catalyst was separated from the mixture with the aid of an external magnet. The residue was filtered off and the precipitate was washed with chloroform. Then, to get rid of the remnants of impurities, the precipitate was poured into a beaker and a little amount of ethanol (less than $0.5 \mathrm{cc}$ ) was added to it. Then a little amount of water $(0.5 \mathrm{cc})$ was added to the beaker until the organic product separated from ethanol as a solid precipitate. After final filtration, the pure products $\mathbf{5 a - 5 0}$ were dried in air and directly characterized by ${ }^{1} \mathrm{H}$ NMR, ${ }^{13} \mathrm{C}$ NMR, FT-IR, CHN, X-ray crystallographic, and melting point analysis.

\section{Declarations}

\section{Acknowledgement}

The authors would like to thank Sharif University of Technology Research Council for partial financial support. 


\section{Author contributions}

F.M.M. is a professor in organic chemistry at SUT. He devised the project and the main conceptual ideas and was in charge of overall direction and planning. B.A. and A.J. are Ph.D. candidate in organic chemistry at SUT. They performed the experiments, analyzed spectra, and wrote the original draft. A.Y.M. is MSc student. She contributed to perform experiments. All authors reviewed the manuscript.

\section{Competing interests}

The authors declare no competing interests

\section{Data availability}

All data generated or analysed during this study are included in this published article and its Supplementary Information files. CCDC-2143633, DOI: 10.5517/ccdc.csd.cc29ymgc contains the supplementary crystallographic data for this paper. These data can be obtained free of charge from The Cambridge Crystallographic Data Centre via https://www.ccdc.cam.ac.uk/structures/.

\section{References}

1. Hasani, M., \& Kalhor, H. R.; ACS Catalysis, 2021, 11(17), 10778-10788.

2. Veisi, H., Abrifam, M., Kamangar, S. A., Pirhayati, M., Saremi, S. G., Noroozi, M., ... \& Karmakar, B. ; Scientific Reports, 2021,11(1), 1-14.

3. Das, A. K., Vemuri, R. S., Kutnyakov, I., McGrail, B. P., \& Motkuri, R. K.;Scientific reports, 2016, 6(1), 1-7.

4. Xie, L. G., Niyomchon, S., Mota, A. J., González, L., \& Maulide, N. ; Nature communications, 2016, 7(1), $1-9$.

5. Moghaddam, F. M., Jarahiyan, A., \& Pourjavadi, A. ;2021, Catalysis Letters, 1-12.

6. Aubin, L. B., Wagner, T. M., Thoburn, J. D., Kesler, B. S., Hutchison, K. A., Schumaker, R. R., \& Parakka, J. P. ; Organic letters, 2001, 3(21), 3413-3416.

7. Dong, Z. B., Liu, X., \& Bolm, C; Organic letters, 2017, 19(21), 5916-5919.

8. Mazzarella, D., Magagnano, G., Schweitzer-Chaput, B., \& Melchiorre, P.; ACS Catalysis,2019,9(7), 5876-5880.

9. Moghaddam, F. M.; Aghamiri, B.; Jalalinik, M.; Synthetic communications, 2021, doi.org/10.1080/00397911.2021.2008445

10. Moghaddam, F. M., Saberi, V., \& Karimi, A.; Scientific reports, 2021,11(1), 1-11.

11. Moghaddam, F. M., Goudarzi, M., Chamani, F., \& Dezag, H. M.; New Journal of Chemistry, 2020,44(23), 9699-9702.

12. Dodd, L. J., Omar, O., Wu, X., \& Hasell, T.; ACS Catalysis, 2021,11(8), 4441-4455.

13. Zhang, Z., Nie, X., Wang, F., Chen, G., Huang, W. Q., Xia, L., ... \& You, Y. Z.; Nature communications, 2020,11(1), 1-10. 
14. Mizojiri, R., Takami, K., Ito, T., Maeda, H., Yamano, M., \& Kawamoto, T. Organic Process Research \& Development, 2017, 21(7), 1034-1041

15. Mizojiri, R., Takami, K., Ito, T., Maeda, H., Yamano, M., \& Kawamoto, T.;Organic Process Research \& Development, 2017,21(7), 1034-1041.

16. Corbet, M.; de Greef, M.; Zard, S. Z. Org. Lett. 2008, 10, 253.

17. Bodaghifard, M. A., Mobinikhaledi, A., \& Asadbegi, S. ; Applied Organometallic Chemistry, 2017, 31(2), e3557.

18. Kaur, N.; Catalysis Letters, 2019,149(6), 1513-1559.

19. Li, J., Liu, J., Liu, S., \& Li, J.; Catalysis Letters,2021,1-8.

20. Dubey, R., Singh, V. K., Sharma, L. K., Upadhyay, A., Kumar, N., \& Singh, R. K. P.; New Journal of Chemistry, 2017, 41(16), 7836-7839.

21. Bio, M. M., Hansen, K. B., \& Gipson, J. ;Organic Process Research \& Development, 2008,12(5), 892895.

22. Brayshaw, S. K., Clarke, L. P., Homanen, P., Koentjoro, O. F., Warren, J. E., \& Raithby, P. R.; Organometallics, 2011, 30(15), 3955-3965.

23. Hutchinson, J. H., Charleson, S., Evans, J. F., Falgueyret, J. P., Hoogsteen, K., Jones, T. R., ... \& McFarlane, C. S.; Journal of medicinal chemistry, 1995, 38(22), 4538-4547.

24. Hepworth, J. D., \& Heron, B. M. ; Heterocyclic Chemistry, 2008, 727-954

25. Tavakolinia, F., Baghipour, T., Hossaini, Z., Zareyee, D., Khalilzadeh, M. A., \& Rajabi, M. ; Nucleic acid therapeutics, 2012, 22(4), 265-270.

26. Pasha, G. F., Asghari, S., Tajbakhsh, M., \& Mohseni, M., Research on Chemical Intermediates, 2017, 43(12), 7291-7306.

27. Verma, R. K., Verma, G. K., Shukla, G., Nagaraju, A., \& Singh, M. S.; ACS combinatorial science, 2012,14(3), 224-230.

28. van Vliet, L. A., Rodenhuis, N., Dijkstra, D., Wikström, H., Pugsley, T. A., Serpa, K. A., ... \& Lundmark, M.; Journal of medicinal chemistry, 2000,43(15), 2871-2882.

29. F. M. Moghaddam and R. Pourkaveh, Catalysis Communications, 2017, 94, 33-37.

30. P. Xiong, H. Zhang, G. Li, C. Liao and G. Jiang, Science of The Total Environment, 2021, 797, 149179.

31. Y. K. Hwang, D. Y. Hong, J. S. Chang, S. H. Jhung, Y. K. Seo, J. Kim, A. Vimont, M. Daturi, C. Serre and G. Férey, Angewandte Chemie, 2008, 120, 4212-4216.

32. Liu, R. et al. Effective and selective adsorption of phosphate from aqueous solution via trivalentmetals-based amino-MIL-101 MOFs. Chemical Engineering Journal 357, 159-168 (2019).

33. Kandiah, M. et al. Post-synthetic modification of the metal-organic framework compound UiO-66. Journal of Materials Chemistry 20, 9848-9851 (2010).

34. Chenampulli, S., Unnikrishnan, G., Thomas, S. \& Narine, S. S. Novel ethylene diamine functionalised nanocellulose/poly (ethylene-co-acrylic acid) composites for biomedical 
35. A. Farisabadi, M. Moradi, S. Hajati, M. A. Kiani and J. P. Espinos, Applied Surface Science, 2019, 469, 192-203.

36. V.-D. Doan, B.-A. Huynh, H. A. Le Pham and Y. Vasseghian, Environmental Research, 2021, 201, 111593.

37. S. Zhao, D. Ma and W. Jin, Journal of Nanomaterials, 2010, 2010, 28.

38. L. He, Y. Dong, Y. Zheng, Q. Jia, S. Shan and Y. Zhang, Journal of hazardous materials, 2019, 361, 8594.

\section{Tables}

Table 1. $\mathrm{N}_{2}$ adsorption-desorption data

\begin{tabular}{|llll|}
\hline Samples & $\mathrm{S}_{\mathrm{BET}}\left(\mathrm{m}^{2} / \mathrm{g}\right)$ & $\begin{array}{l}\text { Total pure volume } \\
\left(\mathrm{cm}^{3} / \mathrm{g}\right)\end{array}$ & $\begin{array}{l}\text { Mean pore diameter } \\
(\mathrm{nm})\end{array}$ \\
\hline Magnetic $\mathrm{NH}_{2} \cdot \mathrm{MIL}-101(\mathrm{Fe})$ & 625.1 & 0.13 & 13.6 \\
\hline $\begin{array}{l}\text { Magnetic } \mathrm{NH}_{2} \cdot \mathrm{MIL}- \\
\begin{array}{l}\text { 101(Fe)/ED } \\
\hline\end{array}\end{array}$ & 582.3 & 0.10 & 15.2 \\
\hline
\end{tabular}

Table 2,3 is available in the Supplemental Files section.

\section{Figures}

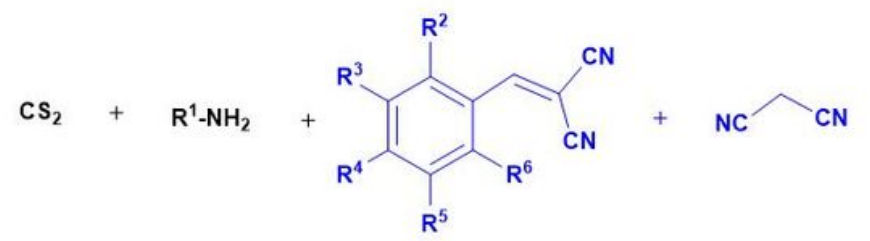

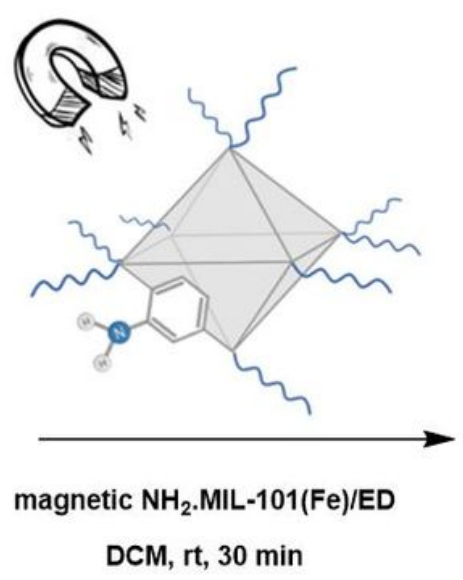

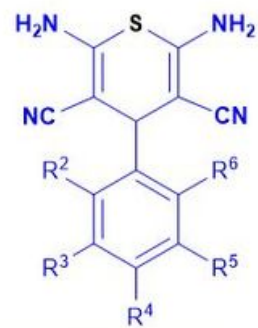


Figure 1

Catalytic activity of magnetic $\mathrm{NH}_{2} \cdot \mathrm{MIL}-101(\mathrm{Fe}) / \mathrm{ED}$ complex for the synthesis of thiopyran derivativs.

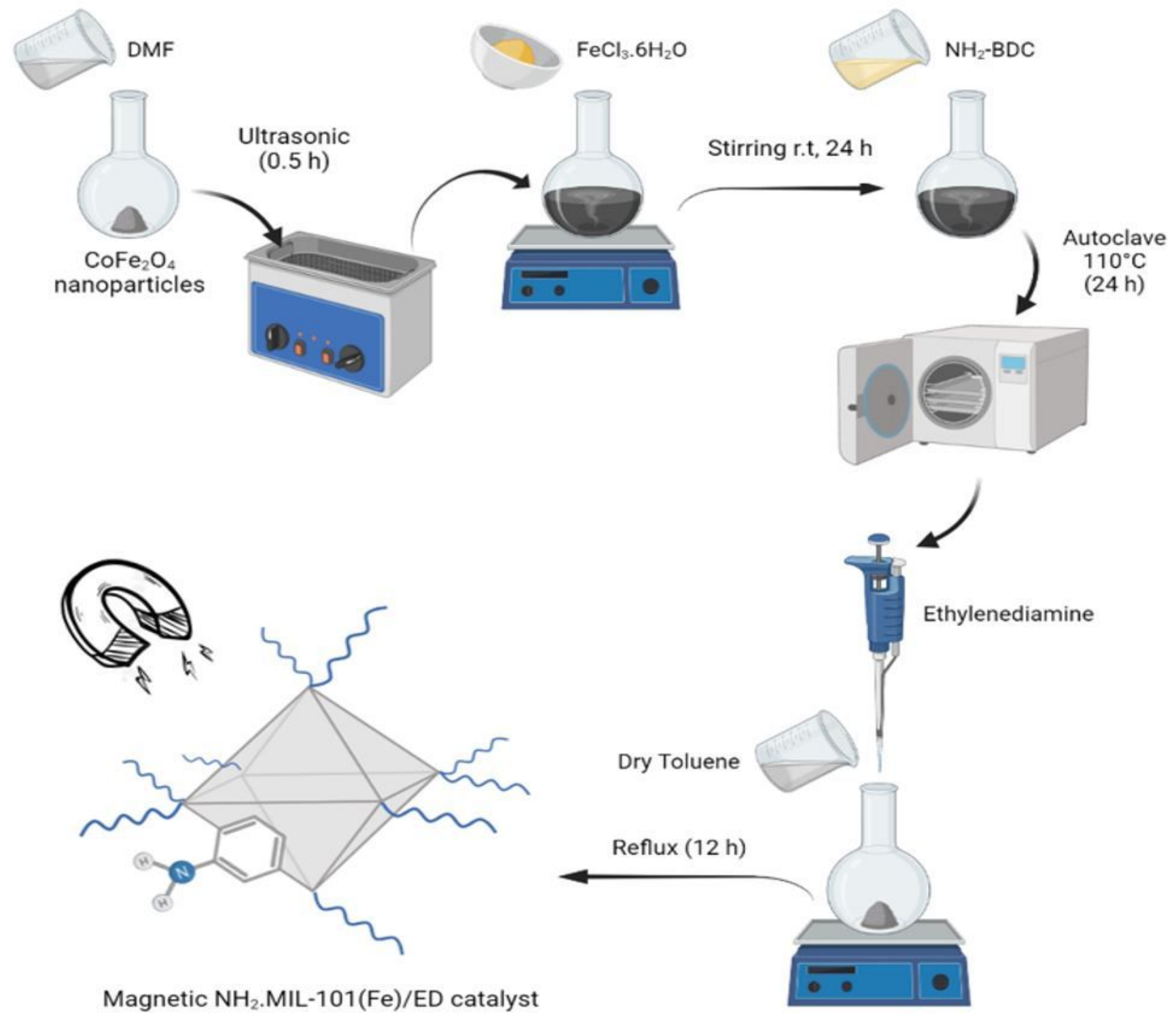

Figure 2

The synthesis procedure of magnetic $\mathrm{NH}_{2} \cdot \mathrm{MIL}-101$ (Fe)/ED catalyst. 


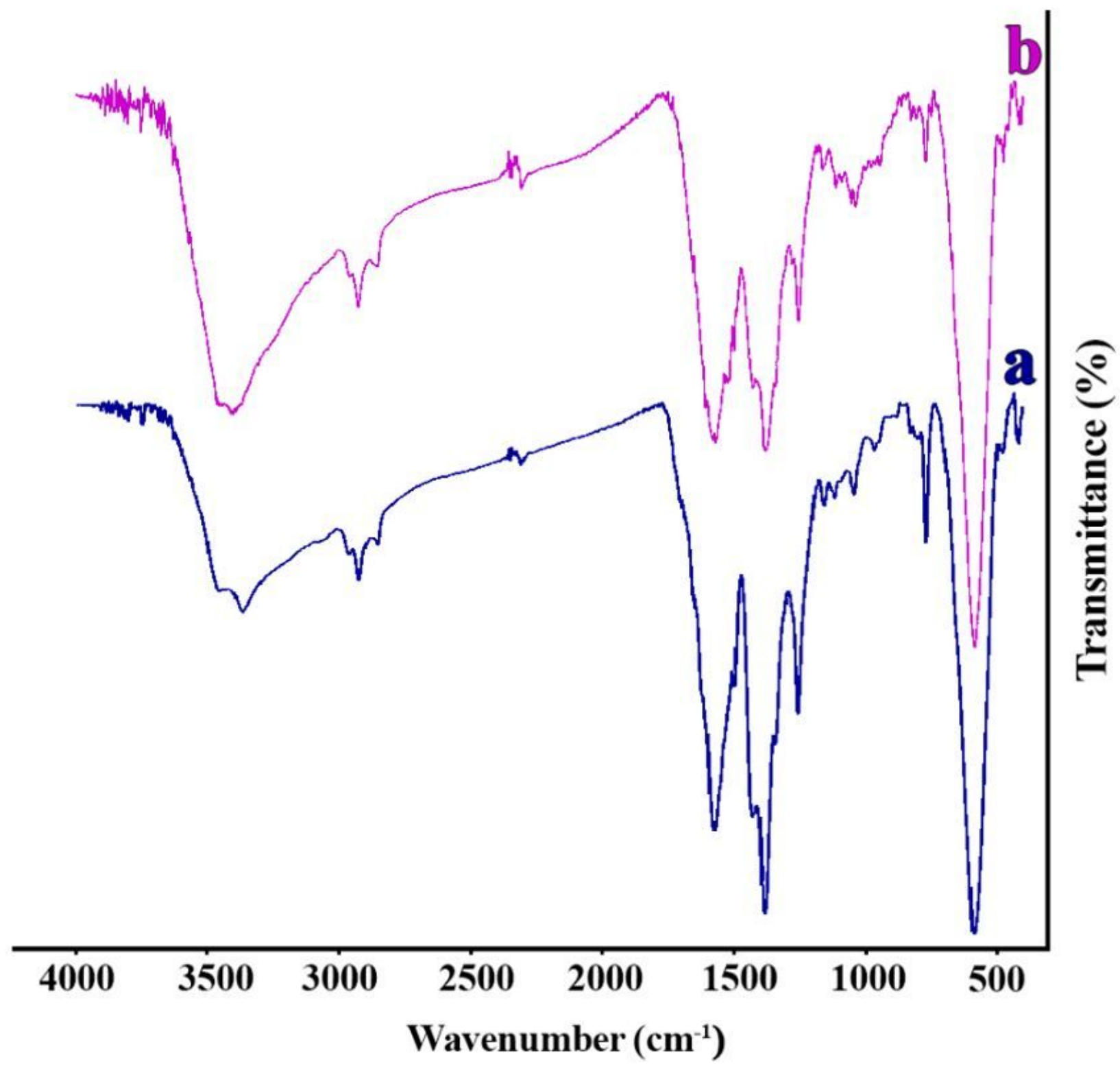

Figure 3

The FT-IR spectra of (a) Magnetic $\mathrm{NH}_{2} \cdot \mathrm{MIL}-101(\mathrm{Fe})$ and (b) Magnetic $\mathrm{NH}_{2} \cdot \mathrm{MIL}-101(\mathrm{Fe}) / \mathrm{ED}$. 


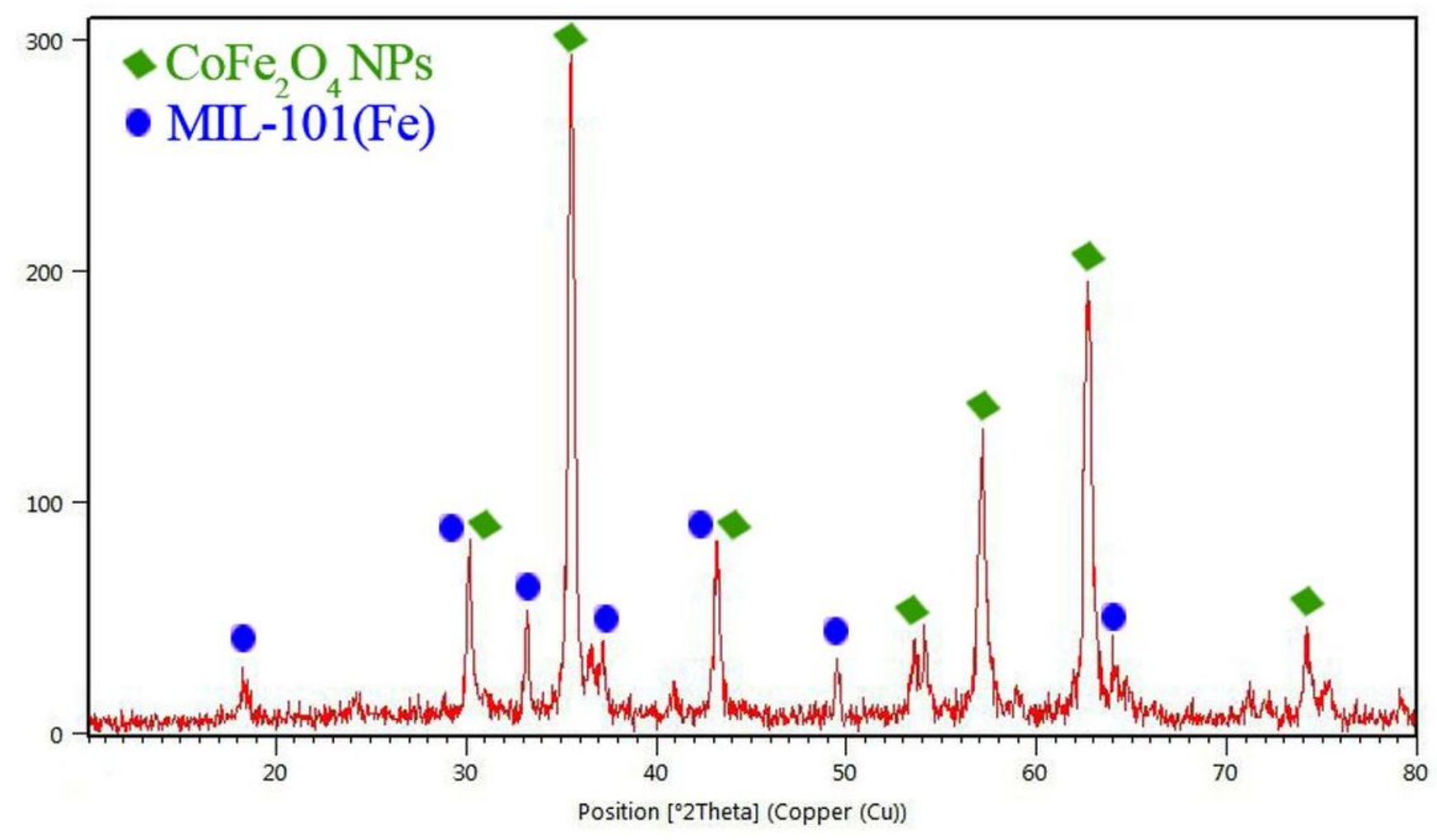

Figure 4

The XRD pattern of magnetic $\mathrm{NH}_{2} \cdot \mathrm{MIL}-101$ (Fe)/ED catalyst.

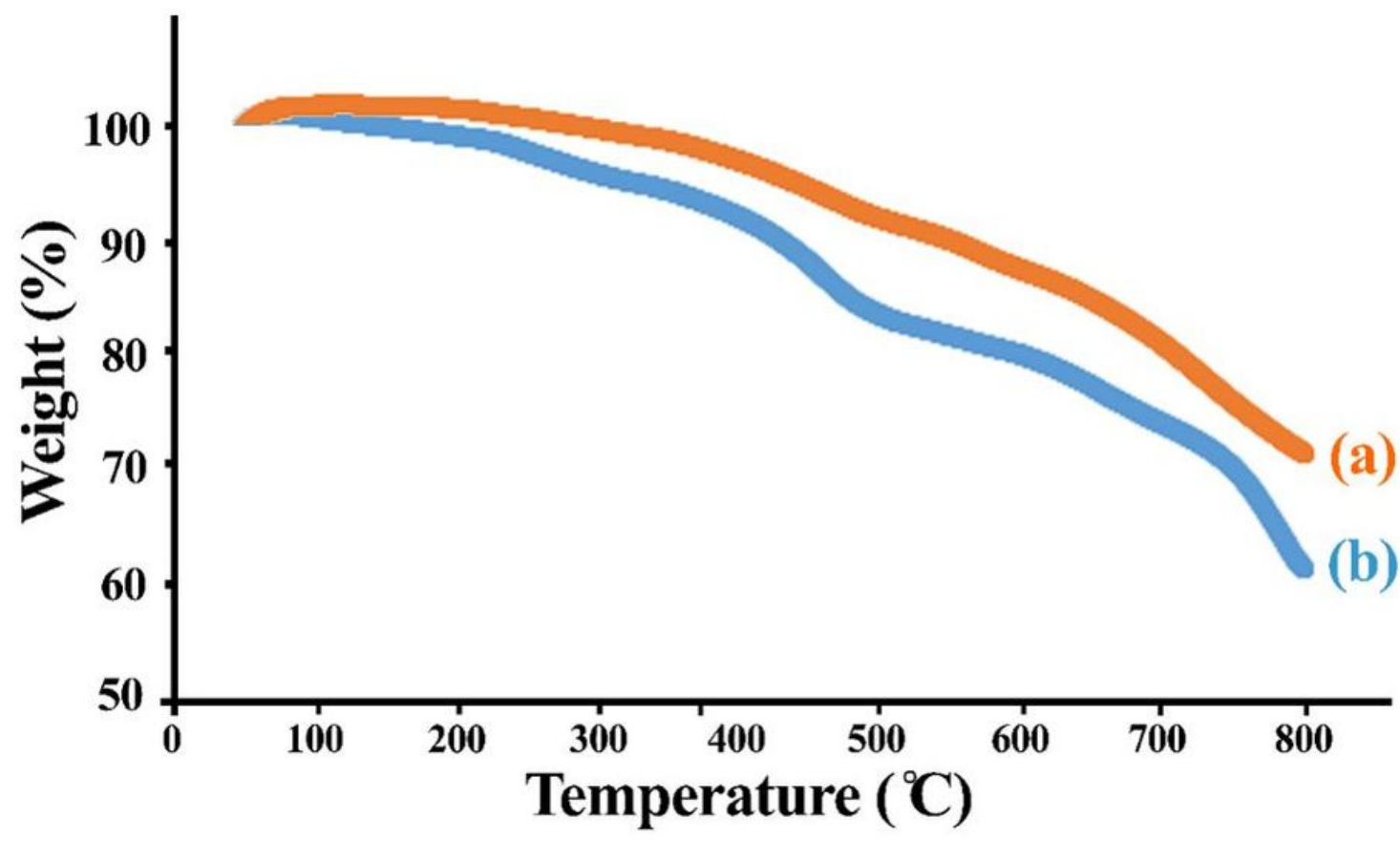




\section{Figure 5}

Thermograms of (a) Magnetic $\mathrm{NH}_{2} \cdot \mathrm{MIL}-101(\mathrm{Fe})$ and (b) Magnetic $\mathrm{NH}_{2} \cdot \mathrm{MIL}-101(\mathrm{Fe}) / \mathrm{ED}$.

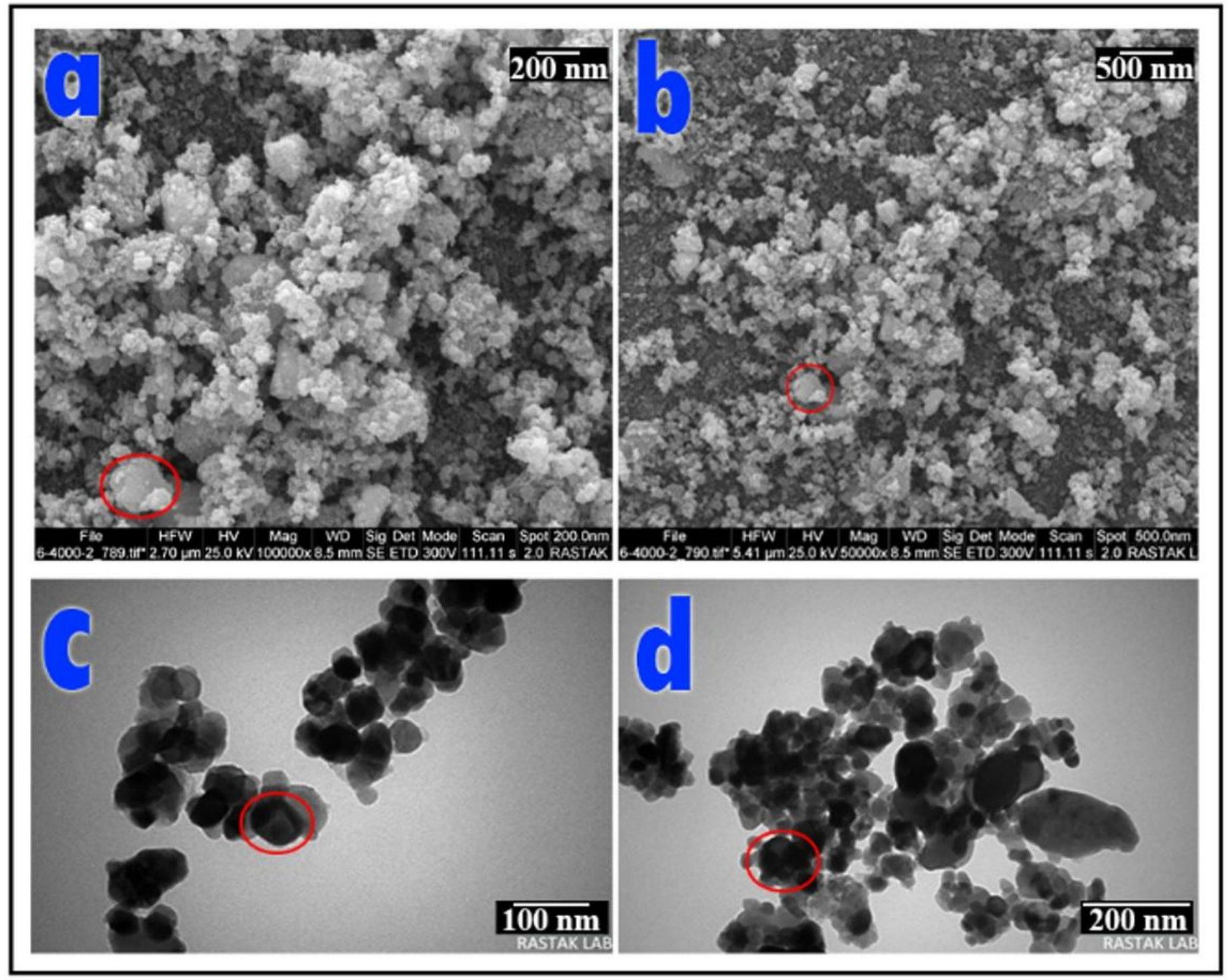

Figure 6

The FE-SEM images of magnetic $\mathrm{NH}_{2} \cdot \mathrm{MIL}-101(\mathrm{Fe}) / \mathrm{ED}(\mathrm{a}$ and $\mathrm{b})$ and the TEM images of magnetic

$\mathrm{NH}_{2} \cdot \mathrm{MIL}-101$ (Fe)/ED (c and d). 


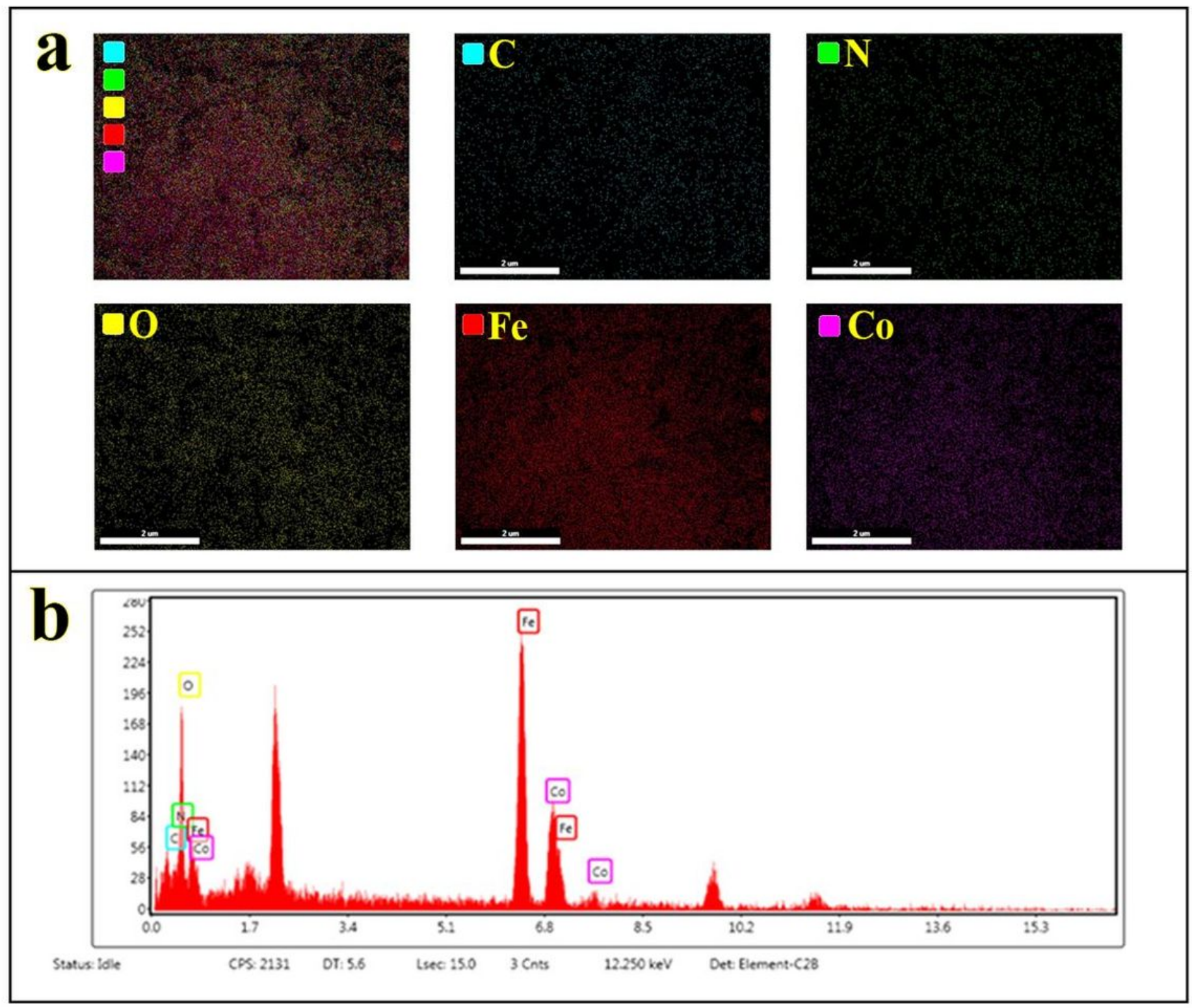

Figure 7

(a) The elemental mapping images of magnetic $\mathrm{NH}_{2} \cdot \mathrm{MIL}-101(\mathrm{Fe}) / \mathrm{ED}$ and (b) the EDX pattern of magnetic $\mathrm{NH}_{2} \cdot \mathrm{MIL}-101(\mathrm{Fe}) / \mathrm{ED}$. 


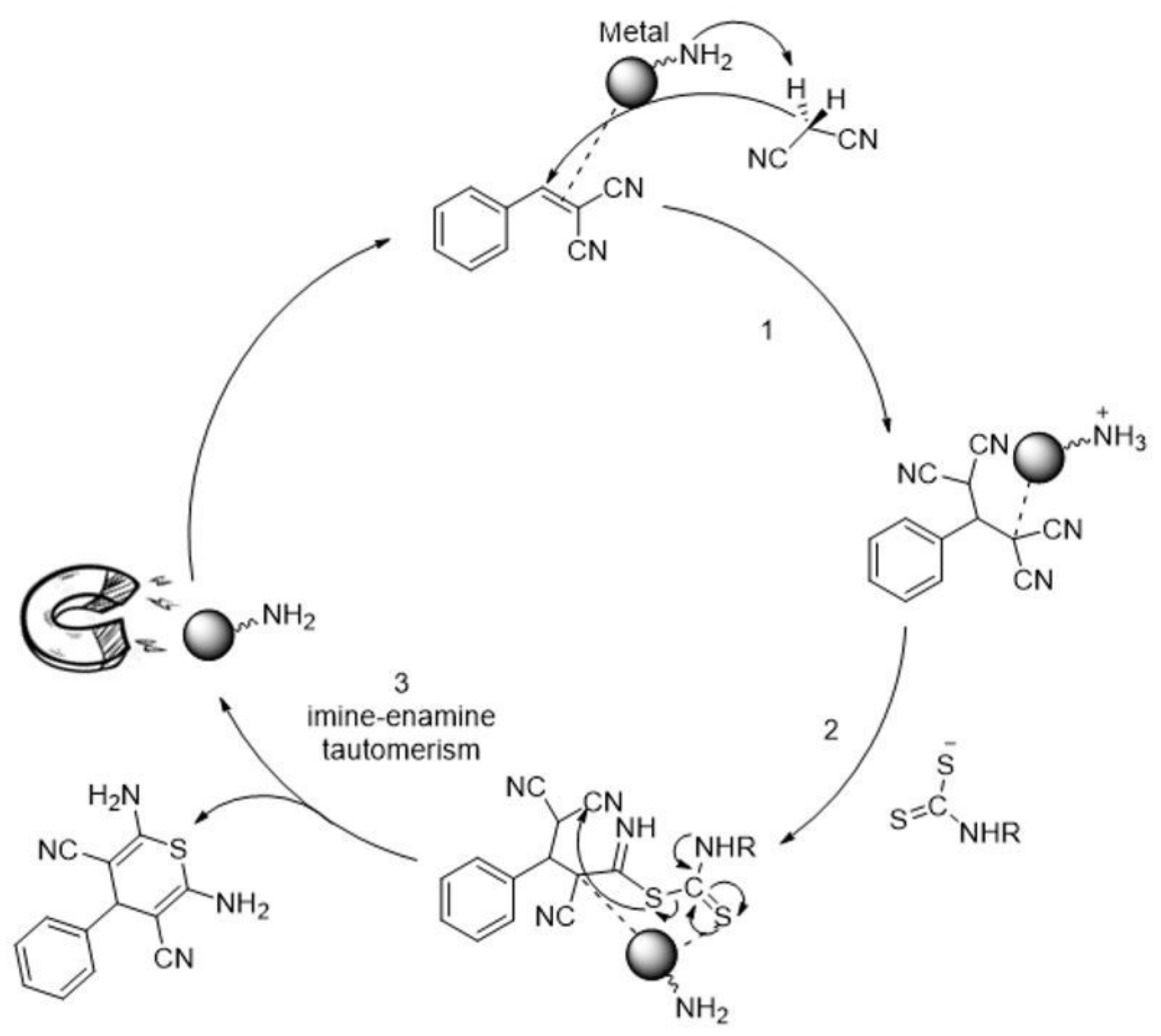

Figure 8

Proposed mechanism

\section{Supplementary Files}

This is a list of supplementary files associated with this preprint. Click to download.

- Table2.jpg

- Table3.jpg

- Supportinginformationrevised.docx 